\title{
Special issue: perspectives on eTourism
}

\author{
Juho Pesonen $^{1}$ · Julia Neidhardt ${ }^{2}$
}

Published online: 27 February 2020

○) Springer-Verlag GmbH Germany, part of Springer Nature 2020

There is no question about the profound impact that information and communication technologies (ICTs) have had and continue to have on travel and tourism. Technology adoption is an ongoing challenge for the tourism industry all over the world. Whereas in more developed countries tourism industry is tackling the issue of service automation and robotics, developing countries are still struggling with the infrastructure required to enable the efficient use of ICTs. There are also constant issues regarding travel and tourism technology inclusiveness.

Tourism marketing is also in constant change as ICTs change and develop. For example, hotels are figuring out if it is the destination or the hotel that they should be promoting in social media. Online travel reviews tremendously influence tourists' decision-making process, especially when choosing a hotel. ICTs can also be utilized to increase the well-being of travelers after the trip when they reminiscence their experiences, assisted by technology.

Technology also enables us to understand tourism in completely new ways. Data available for researchers makes it possible to map how tourists travel the world and understand the characteristics of travelers and destinations.

All of these topics are discussed in this special issue. The presented papers are based on research contributions presented at ENTER2019, the International Information and Communication Technologies in Tourism Conference, which took place in Nicosia, Cyprus, from 29 January to 01 February 2019. This collection provides seven interesting papers, all of them demonstrating how information and communication technologies are impacting various topics in tourism research.

Sanjay Lama, Sojen Pradhan, and Anup Shrestha take a detailed look at e-Tourism adoption in developing countries. Developing countries have different kinds of technological infrastructure and contextual factors compared to more developed countries, and this research conceptualizes the effects of these

Juho Pesonen

juho.pesonen@uef.fi

Julia Neidhardt

neidhardt@ec.tuwien.ac.at

1 University of Eastern Finland, Business School, Joensuu, Finland

2 TU Wien, Research Unit of E-Commerce, Vienna, Austria 
differences. Understanding technology adoption in countries such as Nepal has important policy implications that can direct investments in e-Tourism to increase the impact.

Chun Liu and Kam Hung study how self-service technologies in hotels replace service employees. They found that when managers are making decisions on selfservice technology adoption, they compare the possibilities of the technology to what their service employees can do. Both self-service technology and service employees have advantages and disadvantages that affect the decisions hotel managers make.

Social media is a pervasive technology in hotel marketing. Berta Ferrer-Rosell, Eva Martin-Fuentes and Estela Marine-Roig examine how hotels use Facebook to interact and to establish relationships with their customers, and to provide them with relevant content and information. Hotels generally post either hotel-related information or destination level information. They identify differences in content strategies between hotels in Madrid and Barcelona. Hotels adopt different kinds of social media strategies based on the destination they are located in.

Women are under-represented in decision-making positions in ICT or hightech organizations. Cristina Figueroa-Domecq, Jesus Palomo, Maria Dolores Flecha-Barrio, and Monica Segovia-Pérez study this double gender gap in the tourism industry. Their results, based on analyzing 55 tourism-related firms, confirm the direct relationship between the technological level of the companies on the one hand and the lower participation of women on management teams and board of directors on the other hand.

Bruce Wan, Kenny Chow, Cees de Bont, and Paul Hekkert use travel diaries to study memorable and meaningful tourism experiences. Personal technologies such as digital diary, photocollage, and social media support travelers in capturing and reminiscing about their remarkable holiday moments. Facilitating the creation of visual travel diaries can help to generate various layers of information, such as the emotions, personal preferences and the implicit psychological needs associated with memorable and meaningful travel experiences. There are also considerable benefits to human well-being. The authors also identify differences in structure and content between oral and visual travel narratives.

Linus Dietz, Avradib Sen, Rinita Roy and Wolfgang Wörndl present a datadriven method to mine trips from location-based social networks. This helps to understand how tourists travel the world. They also present two applications that utilize the mined trips. The first one is an approach for clustering travelers, where the pure mobility measures are enriched with social aspects, i.e., the kinds of venues into which the users checked-in. The second application area is the spatial clustering of destinations around the world. Understanding the characteristics of travelers and touristic regions enable us to generate better recommendations for tourists.

In the final paper of this special issue Ludovik Coba, Laurens Rook, and Markus Zanker examine the potential impact of plain rating summary statistics on people's choice behavior. The authors explore the effects of different types of rating attributes on hotel choice behavior. They also investigated whether the effect of rating summary statistics on hotel choice behavior is moderated by a 
person's high or low behavioral maximizing tendency (i.e., how simple or difficult the making of choices from a set of alternatives feels to the decision-maker). To this end, an eye-tracking experiment is conducted.

Publisher's Note Springer Nature remains neutral with regard to jurisdictional claims in published maps and institutional affiliations. 